\title{
RAYLEIGH LIDAR OBSERVATION OF TROPICAL MESOSPHERIC INVERSION LAYER: A COMPARISON BETWEEN DYNAMICS AND CHEMISTRY
}

\author{
K. Ramesh ${ }^{1, * *}$, S. Sridharan ${ }^{1}$, K. Raghunath ${ }^{1}$ \\ ${ }^{1}$ National Atmospheric Research Laboratory (NARL), Gadanki- 517112, A.P., India. \\ * Email: karanamram@gmail.com
}

\begin{abstract}
The Rayleigh lidar at National Atmospheric Research Laboratory, Gadanki $\left(13.5^{\circ} \mathrm{N}, 79.2^{\circ} \mathrm{E}\right)$, India operates at $532 \mathrm{~nm}$ green laser with $\sim 600$ $\mathrm{mJ} / \mathrm{pulse}$ since 2007. The vertical temperature profiles are derived above $\sim 30 \mathrm{~km}$ by assuming the atmosphere is in hydrostatic equilibrium and obeys ideal gas law. A large mesospheric inversion layer (MIL) is observed at $77.4-84.6 \mathrm{~km}$ on the night of 22 March 2007 over Gadanki. Although dynamics and chemistry play vital role, both the mechanisms are compared for the occurrence of the MIL in the present study.
\end{abstract}

\section{INTRODUCTION}

LIDAR (LIght Detection And Ranging) is the most efficient technique to capture the nocturnal mesospheric inversion layers with high spatial and temporal resolution. The term Mesospheric Inversion Layer (MIL) refers to the inversion of temperature gradient from negative to positive superposed upon the characteristically decreasing mesospheric thermal structure. However the causative mechanisms of MILs are quite complex, a few suggested mechanisms for their occurrence are gravity wave breaking, gravity wave-tidal interactions, chemical heating, and planetary wave critical level interaction [1,2]. The study of MILs is essential to understand the energetics in the mesosphere and lower thermosphere (MLT) region. Most of the waves which are generated in the lower atmosphere can propagate to the MLT region with increasing amplitude in response to decreasing density. When the waves break, the energy and momentum carried by the wave will be deposited in the background and thereby modulate the thermal and dynamical structures. In addition, the chemical heating by the dominant exothermic reactions among $\mathrm{H}, \mathrm{O}, \mathrm{O}_{2}, \mathrm{O}_{3}, \mathrm{OH}, \mathrm{HO}_{2}$ enhances the background temperature in the MLT region [3, 4].

In the present study, a large MIL observed on 22 March 2007 over a tropical region, Gadanki $\left(13.5^{\circ} \mathrm{N}, 79.2^{\circ} \mathrm{E}\right)$ has been selected to investigate the dominant causative mechanism using mainly the Rayleigh lidar temperature profiles for the duration of $\sim 6$ hours.

\section{INSTRUMENTATION AND DATA}

\subsection{NARL LIDAR SYSTEM}

The Mie and Rayleigh lidar system installed at National Atmospheric Research Laboratory (NARL), Gadanki $\left(13.5^{\circ} \mathrm{N}, 79.2^{\circ} \mathrm{E}\right)$ employs a Qswitched solid state (Nd:YAG) pulsed laser (PL9050) from Continuum, USA. The system operates at $532 \mathrm{~nm}$ green laser with the pulse repetition frequency (PRF) of $50 \mathrm{~Hz}$ and the energy of $\sim 600 \mathrm{~mJ}$ per pulse. The laser beam diameter is $9 \mathrm{~mm}$ and it will be expanded into 10 times in order to reduce the beam divergence from $\sim 0.45 \mathrm{mRad}$ (before expansion) to less than 0.1 mRad (after expansion) so that the beam remains within the FOV of the receiver system at all ranges of interest. The Mie (Schmidt-Cassegrain telescope) and Rayleigh receivers (Newtonian telescope) collect the atmospheric back scattered photons which are allowed to fall on photo multiplier tubes (PMTs) of different gains. The PMT output signal will be collected and processed through the MCS-plus (Multi Channel Scalar) PC based photon count system which is working with four data acquisition channels, two from Rayleigh receiver ( $R, U$ channels) and two from Mie receiver ( $\mathrm{P}, \mathrm{S}$ channels) for simultaneous photon counting with 12500 laser shots averaged for the 
time resolution of $250 \mathrm{sec}$ with range resolution (dwell time $=2 \mu \mathrm{sec}$ ) of $300 \mathrm{~m}$. For example, the typical MCS photon count profiles for P-channel and R-channel are as shown in Figure 1. More details on NARL lidar system can be obtained from Ramesh and Sridharan, [2012] [5].
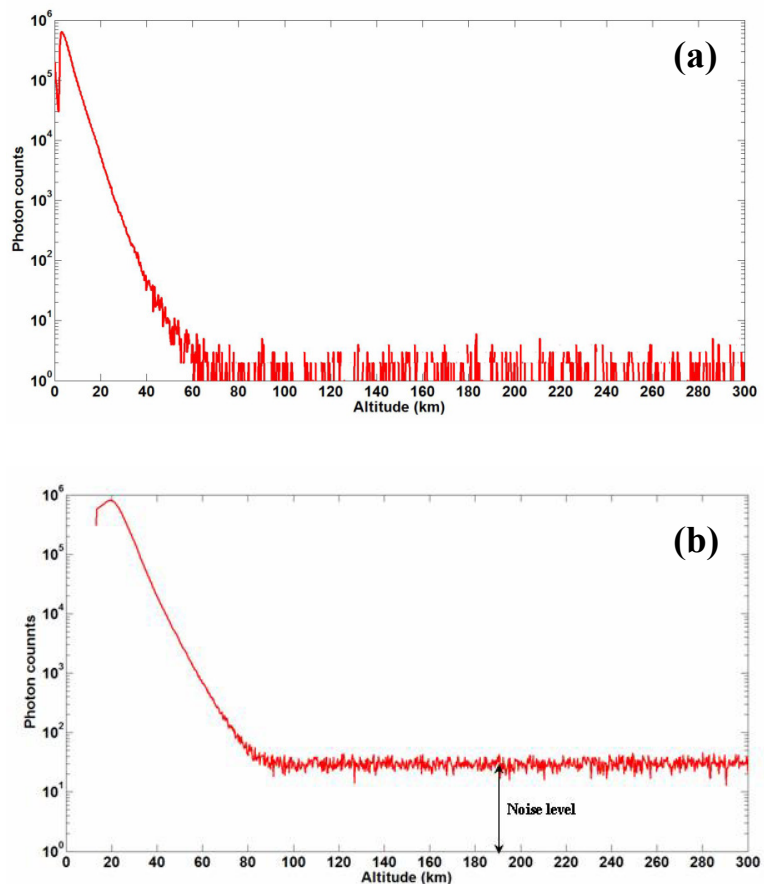

Figure 1 The typical lidar photon count profile for (a) P-channel and (b) R-channel.

\subsection{TIMED-SABER DATA}

The Sounding of the Atmosphere using Broadband Emission Radiometry (SABER) is a space-borne instrument onboard NASA's Thermosphere-Ionosphere-Mesosphere Energetics and Dynamics (TIMED) satellite. It provides vertical profiles of temperature, ozone volume mixing ratio $\left(\mathrm{O}_{3} \mathrm{vmr}\right)$, chemical heating rates due to various exothermic chemical reactions among $\mathrm{H}, \mathrm{O}, \mathrm{O}_{2}, \mathrm{O}_{3}, \mathrm{OH}, \mathrm{OH}_{2}$, and volume emission rates of different species. More details on SABER instrument and different data sets can be obtained from Remsberg et al. [2003] [6], Mlynczak et al. [2007] [7], and Gan et al. [2012] [8].

\section{DATA ANALYSIS}

The lidar temperature profiles are determined from the method given by Hauchecorne and Chanin,

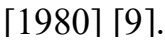

In the height range above $30 \mathrm{~km}$ where the aerosol contribution is negligible (scattering ratio is greater than one calculated from Mie lidar), the range corrected signal and atmospheric transmission is proportional to the molecular number density. Using the number density taken from an appropriate model (MSIS- 90 or CIRA86 ) for the height of $50 \mathrm{~km}$ where the signal-tonoise ratio is fairly high, the constant of proportionality is evaluated and there by the density profile $\mathrm{r}(\mathrm{z})$ is derived. Taking the pressure $(\mathrm{P})$ at the top of the height range $(90 \mathrm{~km})$ from the model, the pressure profile is computed using the measured density profile, assuming the atmosphere to be in hydrostatic equilibrium. Using the ideal gas relation, the temperature at $i^{\text {th }}$ layer $\mathrm{T}\left(\mathrm{z}_{\mathrm{i}}\right)$ is given by

$T\left(z_{i}\right)=\frac{M g\left(z_{i}\right) \Delta z}{R \log (1+X)}$ where $X=\frac{\rho\left(z_{i}\right) g\left(z_{i}\right) \Delta z}{P\left(z_{i}+\Delta z / 2\right)}$

and the statistical standard error in the temperature is given by

$$
\frac{\delta T\left(z_{i}\right)}{T\left(z_{i}\right)}=\frac{\delta \log |1+X|}{\log |1+X|}=\frac{\delta X}{(1+X) \log (1+X)}
$$

\section{RESULTS}

Figure $2 \mathrm{a}$ shows the vertical profiles of nightly mean (19:57-02:37 LT) lidar and SABER $\left(12.7^{\circ} \mathrm{N}\right.$, 82.6 $\left.{ }^{\circ} \mathrm{E}, 01: 00 \mathrm{LT}\right)$ temperatures for 22-23 March 2007. In addition, the corresponding MSIS-90 (Mass Spectrometer Incoherent Scatter-90) model temperature profile also shown here for comparison. The lidar temperature profile show a large inversion layer at $\sim 77.4-84.6 \mathrm{~km}$ with amplitude and thickness of $\sim 34.4 \mathrm{~K}$ and $7.2 \mathrm{~km}$ respectively. The associated errors in the lidar temperature measurement are $0.1 \mathrm{~K}-1.0 \mathrm{~K}$ from 30 $\mathrm{km}$ to $60 \mathrm{~km}, 1.0 \mathrm{~K}-5.0 \mathrm{~K}$ from $60 \mathrm{~km}$ to $80 \mathrm{~km}$ and $5.0 \mathrm{~K}-15.0 \mathrm{~K}$ from $80 \mathrm{~km}$ to $89 \mathrm{~km}$. However the SABER temperature profile shows the inversion layer at $\sim 73.4-81.3 \mathrm{~km}$ with amplitude and thickness of $\sim 31 \mathrm{~K}$ and $7.9 \mathrm{~km}$ respectively. Here, the upper and lower level temperature and height differences give the inversion amplitude and thickness respectively. Figure $2 \mathrm{~b}$ shows the SABER ozone $\left(\mathrm{O}_{3}\right)$ volume mixing ratio (vmr) profile from which it can be observed that there is no enhancement in the $\mathrm{O}_{3} \mathrm{vmr}$ within the inversion layer. 


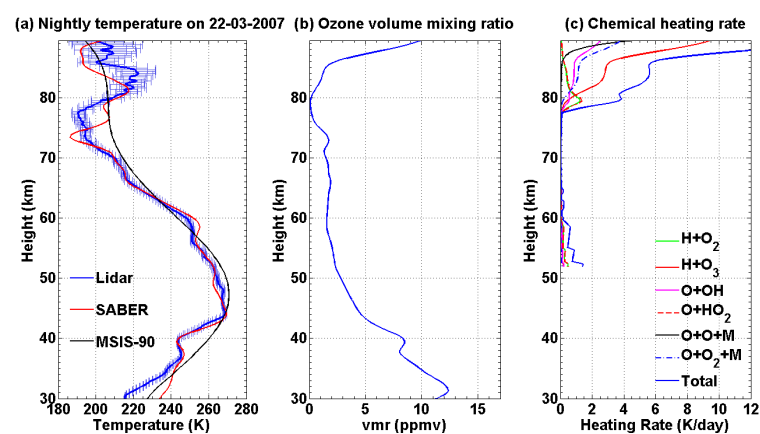

Figure 2 (a) The nightly mean Rayleigh lidar temperature (19:57-02:37 LT) over Gadanki along with TIMED-SABER $\left(12.7^{\circ} \mathrm{N}, 82.6^{\circ} \mathrm{E}, 01: 00 \mathrm{LT}\right)$ and MSIS90 model temperature profiles for 22-03-2007. The horizontal error bars show the uncertainties in the measurement of lidar temperature. (b), (c) The corresponding $\mathrm{SABER} \mathrm{O}_{3} \mathrm{vmr}$ and chemical heating rates.

As shown in Figure 2c, the associated chemical heating rates due to the reactions $\mathrm{O}+\mathrm{OH} \rightarrow \mathrm{H}+\mathrm{O}_{2}$, $\mathrm{H}+\mathrm{O}_{2}+\mathrm{M} \rightarrow \mathrm{HO}_{2}+\mathrm{M}, \mathrm{H}+\mathrm{O}_{3} \rightarrow \mathrm{OH}+\mathrm{O}_{2}, \mathrm{O}+\mathrm{HO}_{2} \rightarrow$ $\mathrm{OH}+\mathrm{O}_{2}, \mathrm{O}+\mathrm{O}+\mathrm{M} \rightarrow \mathrm{O}_{2}+\mathrm{M}, \mathrm{O}+\mathrm{O}_{2}+\mathrm{M} \rightarrow \mathrm{O}_{3}+\mathrm{M}$ and their total increases drastically above $\sim 77 \mathrm{~km}$ with the dominant reaction between $\mathrm{H}$ and $\mathrm{O}_{3} \quad(\sim 3$ $\mathrm{K} /$ day at $\sim 85 \mathrm{~km})$. However the total heating rate varies as 0.1-5.6 K/day at $\sim 77-85 \mathrm{~km}$ which is much smaller than that shown $(\sim 30 \mathrm{~K} /$ day $)$ by Ramesh et al., [2013] [4].

Figure 3 shows the half-hour integrated lidar temperatures and it can observed from this figure that the inversion layer descends between $\sim 80$ and $86 \mathrm{~km}$ at the rate of $(\sim 1.2 \mathrm{~km} / \mathrm{hr})$ diurnal tidal phase speed. Also the maximum inversion temperature decreases from $\sim 286 \mathrm{~K}(\sim 21: 00 \mathrm{hrs})$ to $\sim 223 \mathrm{~K}(\sim 02: 30 \mathrm{hrs})$ between $\sim 80$ and $85 \mathrm{~km}$ during the observation period

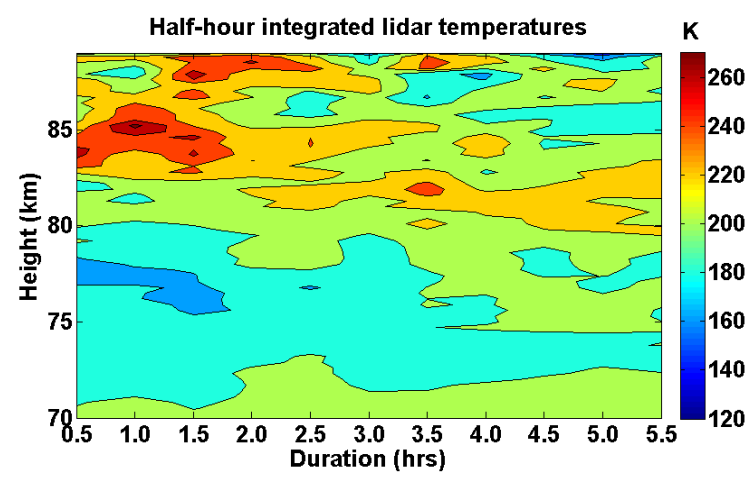

Figure 3 Half-hour integrated Rayleigh lidar temperatures on 22-03-2007 over Gadanki.
Figure 4 shows the 2-dimensional power spectra (FFT) of lidar temperature perturbations and it can be observed from this figure that a small scale gravity wave of $T \sim 38 \mathrm{~min}$ and $\lambda_{\mathrm{z}} \sim 6.4 \mathrm{~km}$ propagates above $\sim 63-82 \mathrm{~km}$ with increasing amplitude at the phase speed of $\mathrm{c}_{\mathrm{z}} \sim 2.8 \mathrm{~m} / \mathrm{s}$.

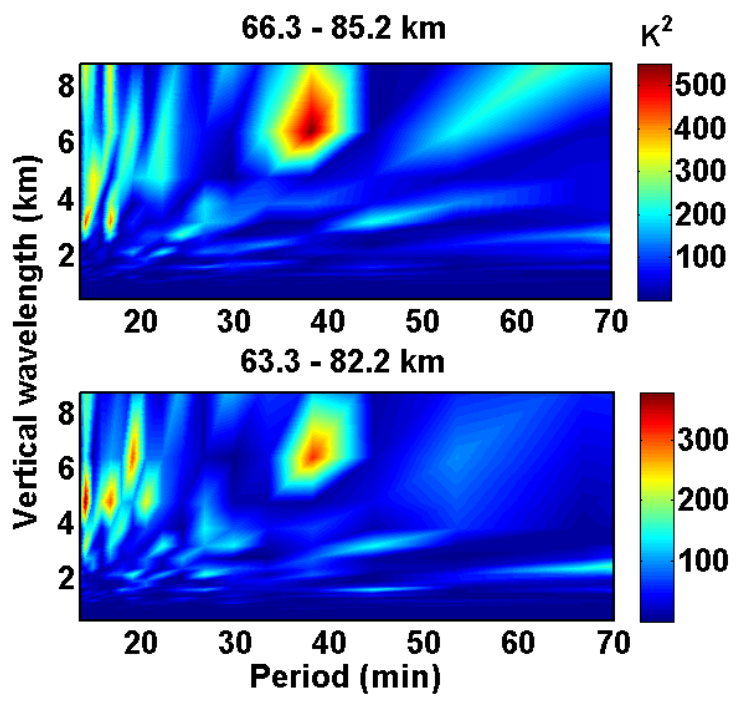

Figure 4 Two dimensional FFT power spectra of lidar temperature perturbations at two different height regions, $63.3-82.2 \mathrm{~km}$ and $66.3-85.2 \mathrm{~km}$.

Further Figure 5 shows the vertical profile of lidar nightly mean Brunt-Väisälä frequency square $\left(\mathrm{N}^{2}\right)$ calculated from the equation (3).

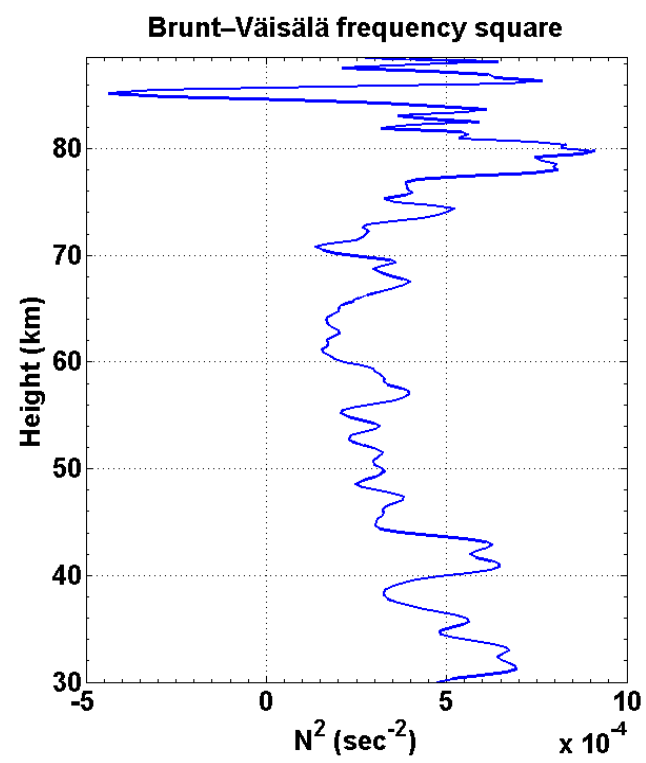

Figure 5 Nightly mean profile of Brunt-Väisälä frequency square for 22-03-2007. 


$$
N^{2}(z)=\frac{g(z)}{T(z)}\left[\frac{d T(z)}{d z}+\frac{g(z)}{c_{p}}\right]
$$

Here $\mathrm{g}(\mathrm{z}), \mathrm{T}(\mathrm{z})$ and $\mathrm{c}_{\mathrm{p}}$ are acceleration due to gravity, mean temperature and specific heat at constant pressure $(1004 \mathrm{~J} / \mathrm{K} / \mathrm{Kg})$ respectively.

From this figure it can be observed that the condition for convective instability $\left(\mathrm{N}^{2}<0\right)$ is satisfied at $\sim 85$ $\mathrm{km}$ which indicates the role of gravity wave breaking for the occurrence of the inversion layer.

\section{SUMMARY AND CONCLUSIONS}

In the present study, the dominant causative mechanism for the occurrence of a large MIL has been investigated mainly using the Rayleigh lidar observations for 22 March 2007 over Gadanki. A small scale gravity wave $\left(T \sim 38 \mathrm{~min}, \lambda_{z} \sim 6.4\right)$ which is propagated from the lower atmosphere attains maximum amplitude at $\sim 85 \mathrm{~km}$ and breaks at this height region $\left(\mathrm{N}^{2}<0\right)$. Due to the wave breaking, the heat and momentum flux carried by the wave is deposited in the background and cause the inversion layer. The inversion layer descends at the rate of diurnal phase speed which gives the evidence for the gravity wave tidal interaction during this MIL event. However the smaller values of $\mathrm{O}_{3} \mathrm{vmr}$ and chemical heating rates suggest their negligible role for the occurrence of this MIL.

\section{ACKNOWLEDGEMENTS}

The authors thank the technical staff for operating and maintaining the Rayleigh lidar system at NARL, Gadanki. They also gratefully acknowledge the NASA's TIMED-SABER team for providing the data used in this study through the website: http://saber.gats-inc.com/.

\section{REFERENCES}

[1] Meriwether, J.W., Gerrard, A.J., 2004: Mesosphere inversion layers and stratosphere temperature enhancements, Rev. of Geophys., 42, RG3003 http://dx.doi.org/10.1029/2003RG000133.
[2] Meriwether, W.J., Gardner, C.S., 2000: A review of the mesospheric inversion layer phenomenon, J. Geophys. Res., 105, 1240512416.

[3] Mlynczak, M. G., Solomon, S., 1993: A detailed evaluation of heating efficiency in the middle atmosphere, J. Geophys. Res., 98, 10,51710,541 .

[4] Ramesh, K., Sridharan, S., Vijaya Bhaskara Rao, S., 2013: Dominance of chemical heating over dynamics in causing a few large mesospheric inversion layer events during January-February 2011, J. Geophys. Res. Space Physics, 118, 67516765, doi:10.1002/jgra.50601.

[5] Ramesh, K., Sridharan, S., 2012: Large mesospheric inversion layer due to breaking of small-scale gravity waves: Evidence from Rayleigh lidar observations over Gadanki $\left(13.5^{\circ} \mathrm{N}\right.$, 79.2 $\left.{ }^{\circ} \mathrm{E}\right)$, J. Atmos. Sol. Terr. Phys., 89, 90 - 97.

[6] Mlynczak, M. G., Marshall, B. T., MartinTorres, F. J., Russell III, J. M., Thompson, R. E., Remsberg, E. E., Gordley, L. L., 2007: Sounding of the Atmosphere using Broadband Emission Radiometry observations of daytime mesospheric $\mathrm{O}_{2}\left({ }^{1} \Delta\right) 1.27 \mu \mathrm{m}$ emission and derivation of ozone, atomic oxygen, and solar and chemical energy deposition rates, J. Geophys. Res., 112, D15306, doi:10.1029/2006JD008355.

[7] Remsberg, E., Lingenfelser, G., Harvey, V. L., Grose, W., Russell III, J.M., Mlynczak, M., Gordley, L., Marshall, B.T., 2003: On the verification of the quality of SABER temperature, geopotential height, and wind fields by comparison with Met Office assimilated analyses, J. Geophys. Res., 108(D19), 4628, doi:10.1029/2003JD003720.

[8] Gan, Q., Zhang, S. D., Yi, F., 2012: TIMED/SABER observations of lower mesospheric inversion layers at low and middle latitudes, J. Geophys. Res., 117, D07109, doi:10.1029/2012JD017455.

[9] Hauchecorne, A., Chanin, M.L., 1980: Density and temperature profiles obtained by lidar between 35 and 70 km, Geophys. Res. Lett., 7, 565-568. 